\title{
Evaluation of the Impact of Light Source on Reproductive Parameters in Laying Hens Housed in Individual Cages
}

\author{
Mikayla Baxter and Grégoy Y. Bédécarrats \\ Department of Animal Biosciences, University of Guelph, Guelph, Ontario, N1G2W1, Canada
}

\begin{abstract}
Higher light wavelengths have been shown to stimulate extra-retinal photoreceptors more efficiently than lower wavelengths to promote reproduction in poultry. We developed a light emitting diode (LED) bulb that emits $60 \%$ of its light in the red spectrum (LED-R), and evaluated the effects of different light sources on growth and reproduction in commercial layer hens. Three rooms equipped with either $100 \mathrm{~W}$ incandescent, $15 \mathrm{~W}$ compact fluorescent (CFL), or $10 \mathrm{~W}$ LED-R bulbs were populated with 96 Lohmann LSL-Lite layers housed in individual cages from 14 to 69 weeks of age (woa). Pullets were initially maintained on a 10-h photoperiod, then photostimulated at 18 woa. Surprisingly, regardless of the light source, plasma levels of estradiol peaked at 16 woa, 2 weeks before photostimulation, and egg-laying was initiated at 19 woa. As a direct correlation between age at first egg and body weight was identified, metabolic cues most likely served as a primary trigger to initiate sexual maturation prior to photostimulation. Overall egg production and cumulative egg numbers were similar among treatments. Interestingly, a second increase in estradiol was observed at 52 woa under all treatments, suggesting an additional ovarian stimulation, possibly associated with an additional follicular recruitment at that age. Overall, changes in estradiol concentrations were more pronounced in hens maintained under LED-R light than in hens exposed to incandescent and CFL, especially for the second increase, suggesting that a higher amount of red light leads to stronger ovarian activity. Maintaining hens under LED-R bulbs also resulted in lower feed consumption, which combined with the lower energy consumption of LED-bulbs (LED-R: $306 \mathrm{~kW}$; incandescent: 2,514kW; CFL: $422 \mathrm{~kW}$ ) could reduce the production cost.
\end{abstract}

Key words: layers, lighting, reproduction, spectrum

J. Poult. Sci., 56: 148-158, 2019

\section{Introduction}

The avian reproductive axis is regulated by two neuropeptides: the inhibitory neuropeptide gonadotropin inhibitory hormone $(\mathrm{GnIH})$ and the stimulatory gonadotropin releasing hormone-I (GnRH-I) (Bédécarrats, 2015). Hypothalamic GnRH-I stimulates the synthesis and release of luteinizing hormone and follicle stimulating hormone from the anterior pituitary gland, which in turn stimulate follicular maturation and steroidogenesis, and trigger ovulation in females (Robinson and Etches, 1986; Mans and Taylor, 2008). Estradiol produced by the outer theca layer of the small follicles stimulates the development of the reproductive tract and the expression of secondary sex characteristics and behavior (Robinson and Etches, 1986; Rangel and Gutierrez, 2014), and is involved in the negative feedback to the hypothalamus and pituitary (Terada et al., 1997). Furthermore, estradiol is

Received: April 26, 2018, Accepted: July 17, 2018

Released Online Advance Publication: October 25, 2018

Correspondence: Dr. Grégoy Bédécarrats, Professor, Department of Animal Biosciences, University of Guelph, Guelph, ON, N1G 2W1, Canada. (E-mail: gbedecar@uoguelph.ca) involved in stimulating the hepatic synthesis of major yolk components, switches bone metabolism towards medullary formation rather than cortical growth, and increases the activity of calcitriol, which increases calcium levels in the blood making it available for shell synthesis (for review: Etches, 1996; Bain et al., 2016). Conversely, progesterone produced by the granulosa cells of the large follicles regulates ovulation (Robinson and Etches, 1986; Ottinger and Bakst, 1995; Rangel and Gutierrez, 2014). On the contrary, $\mathrm{GnIH}$ inhibits the reproductive axis by acting directly on hypothalamic GnRH-I neurons to decrease their activity (Bentley et al., 2003; Ubuka et al., 2008) and on the anterior pituitary by inhibiting the synthesis and release of gonadotropins (Ubuka et al., 2006).

In controlled environments, the reproductive axis can be regulated by manipulating the photoperiod; GnRH-I mRNA and peptide levels increase when day length increases, activating pituitary gonadotropes, and consequently, the ovary, to stimulate steroidogenesis (Dunn and Sharp, 1999; Thayananuphat et al., 2007; Shimizu and Bedecarrats, 2010). This effect is mediated largely by deep brain photoreceptors, the location and pathways of which have been recently 
reviewed by Kuenzel et al. (2015). On the contrary, the inhibitory pathway $(\mathrm{GnIH})$ is regulated by melatonin (Ubuka et al., 2005; Chowdhury et al., 2010, 2013), which is synthesized during the scotophase and is most prevalent under non-stimulatory photoperiods (typically $<12 \mathrm{~h}$ ). Following photostimulation, the increasing amounts of gonadal steroids (estradiol and progesterone) provide feedback to the pituitary to decrease $\mathrm{GnIH}$ receptor mRNA expression (Maddineni et al., 2008). In addition, an increase in day length decreases the amount of melatonin, decreasing $\mathrm{GnIH}$, thus removing the inhibition of the stimulatory branch (Bedecarrats et al., 2009).

Besides the photoperiod, the light characteristics, specifically, the number of photons delivered to the bird and the spectral output, are also important. Higher wavelengths are able to penetrate through the skull and brain tissue more easily to stimulate the hypothalamic photoreceptors (Pang et al., 1974; Foster and Follet, 1985; Oishi and Ohashi, 1993; Mobarkey et al., 2010). Accordingly, red light is the most effective in activating the reproductive axis (Gongruttananun, 2011; Baxter et al., 2014). Conversely, lower wavelengths (blue/green light) require higher intensities to stimulate hypothalamic photoreceptors (Pang et al., 1974), and experimental evidence suggests that green light may inhibit reproduction in birds via retinal photoreceptors (Siopes and Wilson, 1980; Mobarkey et al., 2010; Gongruttananun, 2011; Mobarkey et al., 2013). The light spectrum also affects growth, and previous studies on broilers have indicated that green and blue light stimulate skeletal muscle satellite cell proliferation and myofiber growth, and may stimulate protein synthesis (Halevy et al., 1998; Rozenboim et al., 2004; Cao et al., 2008). Although the effects of green light on growth in layers is not as well documented, similar results have been observed in hens and cockerels, where exposure to green light led to a higher body growth rate (Foss et al., 1972; Baxter et al., 2014).

In practice, a variety of luminaires with different complex spectral compositions are commonly used in the poultry industry, and it is unclear how the spectral composition of these light sources affects the reproductive axis of commercial laying hens. Historically, the primary light source used by the North American poultry industry has been incandescent bulbs with a broad spectral output (400-1050 $\mathrm{nm}$ ) and a gradual peak at $925 \mathrm{~nm}$, mimicking sunlight (Siopes and Wilson, 1980; Chignell et al., 2008). However, these bulbs emit light by heating a tungsten filament, which is very energy-inefficient, and their sale is progressively being phased out in Canada. The two main alternative light sources are fluorescent light and light emitting diodes (LEDs). Fluorescent bulbs have a spectral output of 400$750 \mathrm{~nm}$, with sharp narrow peaks in the green spectrum (558 nm) (Siopes and Wilson, 1980; Chignell et al., 2008). Although fluorescent lighting is more energy-efficient, they do not dim well, can flicker, and contain mercury vapor that requires specialized removal procedures when lamps are discarded in large quantities (Benson et al., 2013). LEDs are among the most energy-efficient light sources, can be manufactured to deliver a defined and stable spectral output (Steranka et al., 2002), and are fully dimmable (Benson et al., 2013). Our previous research on a strain of blind Leghorn called Smoky Joes revealed that light from the red spectrum is instrumental in triggering and maintaining egglaying, independently of the retina (Baxter et al., 2014). Thus, to take advantage of the effects of red light on reproduction while maintaining vision in a broad spectrum, we designed an LED bulb that emits $60 \%$ red, $20 \%$ green, and $20 \%$ blue light, specifically for laying hens.

The purpose of the current study was to evaluate the effects of three different light sources, $100 \mathrm{~W}$ incandescent bulbs, $15 \mathrm{~W}$ compact fluorescent (CFL) lamps, and $10 \mathrm{~W}$ LED bulbs with $60 \%$ red light (LED-R), on reproduction, growth, and feed consumption in birds housed in individual cages. In addition, energy consumption for each light source was recorded over an entire production cycle.

\section{Materials and Methods}

\section{Experimental Birds, Housing Conditions, and Lighting}

Day-old Lohmann LSL-Lite chicks were purchased from Archer's Poultry Farm (Brighton, Ontario, Canada) and raised at the research station of the University of Guelph. From days one to three, the chicks were maintained on $23 \mathrm{~h}$ of light at 20 lux under incandescent lighting. The photoperiod was reduced to $16 \mathrm{~h}$ at 4 days of age, and at 1 week of age (woa) a step-down protocol was implemented (14 h at 1 woa, $13 \mathrm{~h}$ at 3 woa, $12 \mathrm{~h}$ at 4 woa, $11 \mathrm{~h}$ at 5 woa, $10 \mathrm{~h}$ at 6 woa, and $9 \mathrm{~h}$ from 7 to 13 woa). At 14 woa, 288 birds were randomly transferred to one of three separate, identical experimental rooms $(n=96$ per room) equipped with individual cages and illuminated with either ten $100 \mathrm{~W}$ incandescent bulbs (Power Surge, Philips, The Netherlands), $15 \mathrm{~W}$ compact fluorescent (CFL, TCP, TrueDim Lamps; Aurora, Ohio, USA) or $10 \mathrm{~W}$ LED bulbs emitting $60 \%$ red $(668 \mathrm{~nm})$, $20 \%$ green $(523 \mathrm{~nm})$, and $20 \%$ blue $(463 \mathrm{~nm})$ light (LED-R, supplied by Thies Electrical Distributing Inc., Cambridge, Ontario, Canada). Intensity was adjusted to 10 lux at the hens' level and spectral output was measured using a spectrophotometer at placement (14 woa) and at 39, 44, 46, 50, 57, 67, and 69 woa. From 14 to 18 woa, the photoperiod was set to $10 \mathrm{~h}$ and, at 18 woa, the birds were photostimulated using a step-up lighting program increasing photoperiod by $1 \mathrm{~h}$ every two weeks until $14 \mathrm{~h}$ of light. The birds had ad libitum access to commercial diets meeting or exceeding NRC requirements (1994), with a standard poultry chick starter (crumbles) from 0-6 woa, a standard poultry grower (crumbles) from 7-16 woa, and a standard layer-breeder ration (crumbles) from 17 woa to the end of the trial. All animal procedures were reviewed and approved by the University of Guelph Animal Care Committee and strictly adhered to the guidelines of the Canadian Council on Animal Care (CCAC).

To measure the electric energy consumption of the different light sources, a residential electrical meter was installed on the line after the light controller in each room (I210 + Smart Grid Meter; GE Digital Energy, Markham ON, Canada). 
Measurement of Body Weight Gain, Feed Consumption, and Egg Production Parameters

At 14 woa, the birds were weighed to determine their initial body weight, which was used as a reference point to measure body weight gain. Body weights were recorded weekly from 14-31 woa and throughout the trial at 41, 46, 52, 60, and 69 woa. To measure feed consumption, containers were assigned to groups of eight hens (12 containers per room) and were weighed weekly. Individual egg production was recorded daily throughout the trial and reproductive performance was expressed as the average percent weekly production (egg/hen/day over a week). Sexual maturity was determined by recording the age at first egg for each hen. Egg quality was assessed by measuring egg weight and shell strength using the Egg Forces Reader (Orka Food Technology ltd, Bountiful, Utah, USA). Eggs were collected for five consecutive days and egg weights were recorded at $24,35,50$, and 65 woa, whereas shell strength was recorded at 35,50 , and 65 woa.

\section{Estradiol Immuno-assays}

Blood samples were taken from the wing veins of the same 16 birds (four birds per row of cages) in each room at approximately 8:30 am on each sampling day. Serial blood samples were taken biweekly from 13 to 25 woa, and at 29 , $33,37,41,45$, and 49 woa. Approximately $2 \mathrm{~mL}$ of blood was collected and placed in a sodium heparin Vacutainer (Becton, Dickinson and Company, Franklin Lakes, New Jersey, USA). Immediately after collection, plasma was col- lected by centrifugation at $900 \times g$ for $15 \mathrm{~min}$ at $4^{\circ} \mathrm{C}$ and was stored at $-20^{\circ} \mathrm{C}$ until hormone extraction and assay. Estradiol extraction and assays were previously validated for chicken plasma and were described by Baxter et al. (2014). The intra- and inter-assay coefficients of variation were $<15 \%$.

\section{Statistical Analysis}

Since one room was used per light source $(n=1)$, the light treatments could not be statistically compared. Egg production, egg weight, shell strength, feed consumption, body weight (kg), body weight gain (\%), and circulating levels of estradiol were compared over time for each light source, using one-way ANOVA followed by a Tukey's multiple comparison post-hoc test in JMP Statistical Discovery from SAS (JMP Software, Cary, NC, USA). Significance was based on $P<0.05$. To determine whether body weight was correlated with sexual maturation, correlation was calculated using GraphPad Prism 5 (GraphPad Software, Inc., La Jolla, CA, USA) where age at first egg was compared to the birds' body weight, regardless of light treatment at 19 and 20 woa.

\section{Results}

\section{Estradiol}

As shown in Fig. 1, estradiol levels peaked prior to photostimulation at 16 woa under all 3 light sources $(P<0.0001)$. Overall, birds under LED-R light treatment had the highest average levels of estradiol. Interestingly, at 52 woa, a second increase in circulating estradiol levels was observed in all

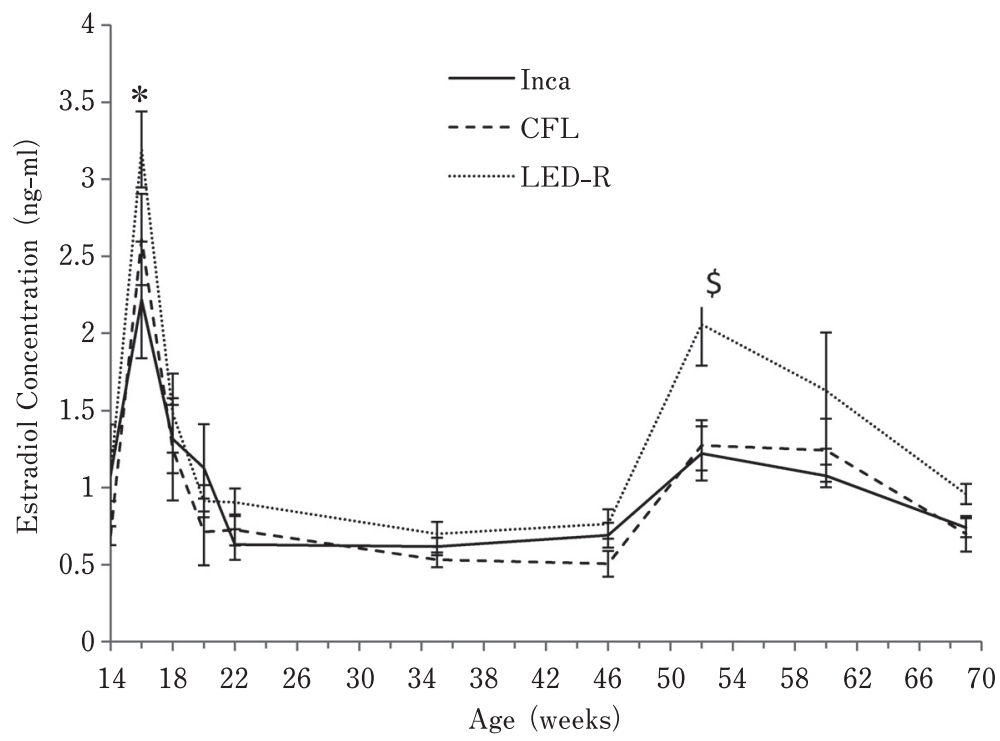

Fig. 1. Plasma estradiol concentrations in hens maintained in individual cages under different light sources. Levels in estradiol in plasma were measured by immuno-assay on serial blood samples collected from 16 birds (four birds per row of cages) taken biweekly from 13 to 25 woa, and at $29,33,37,41,45$, and 49 woa. * denotes a significant difference $(P<0.0001)$ with the previous data point for each individual light treatment. \$ denotes a significant difference $(P<0.05)$ in estradiol concentration observed at 52 woa for hens under LED-R light. 


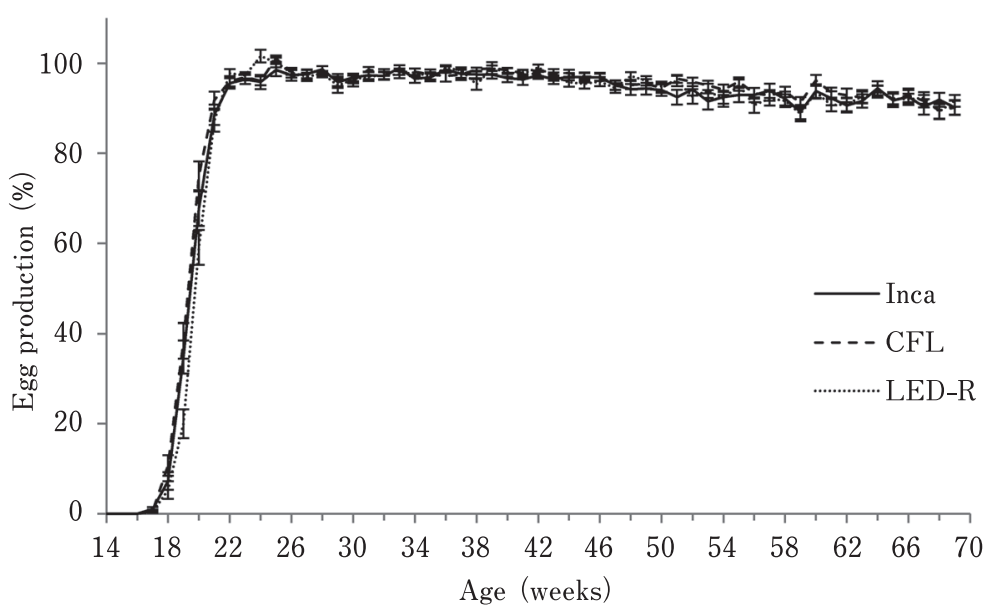

Fig. 2. Egg production of hens maintained in individual cages under different light sources. Egg production was measured daily for each individual hen and averaged per room per week (expressed as hen/egg/day).

Table 1. Age at first egg (mean \pm SEM) and total number of eggs produced per hen (mean \pm SEM) for each light source

\begin{tabular}{lcc}
\hline \hline & Age at first egg (days) & Total egg number \\
\hline Inca & $137.4 \pm 0.57$ & $334.0 \pm 2.51$ \\
CFL & $137.4 \pm 0.65$ & $339.5 \pm 1.26$ \\
LED-R & $140.8 \pm 0.67$ & $334.6 \pm 1.83$ \\
\hline
\end{tabular}

hens, regardless of the light source. However, this second increase in estradiol was significant only in birds under LEDR.

\section{Egg Production}

Age at first egg and total egg number per hen are displayed in Table 1. Birds under LED-R light displayed a slight delay in age at first egg compared to birds under CFL and incandescent light. However, the average age at first egg for all light sources occurred between 19 and 20 woa when birds were under $11-12 \mathrm{~h}$ of light, confirming that birds began to mature before reaching a stimulatory photoperiod, regardless of light treatment.

Egg production was measured over 55 weeks (14-69 woa) and is presented in Fig. 2. Overall, egg production followed a similar pattern for all light treatments, reaching peak production at 22 woa, although average egg production for birds under incandescent light reached the maximum $(99.03 \%)$ at 25 woa, slightly decreased by 59 woa $(90.04 \%)$, and remained constant until 69 woa $(91.17 \%)$. Similarly, birds under CFL reached maximum production (101.12\%) at 25 woa, followed by a slight drop $(90.58 \%)$ at 68 woa. Birds under LED-R light reached maximum production (101.69\%) at 24 woa, and after a slight decrease at 59 woa $(88.76 \%)$, progressively increased back to $91.17 \%$ by 69 woa. The total cumulative number of eggs laid per hen ranged between 334 and 339 , depending on the light source (Table 1).

\section{Egg Weight and Shell Strength}

Egg weight was measured at 24, 35, 50, and 65 woa, and the results are displayed in Fig. 3A. Egg weight increased as birds aged, regardless of the light source $(P<0.0001)$. However, average egg weight reached a maximum by 50 woa for hens under CFL, whereas the increase was more progressive and prolonged until 65 woa for hens under incandescent and LED-R light. Shell strength, measured in kg-force required to crack the egg, was measured at 35,50 , and 65 woa, and the results are displayed in Fig. 3B. As birds aged, a similar, significant decrease in shell strength was observed under all three light sources $(P<0.0001)$.

\section{Feed Consumption}

With an average of $99 \mathrm{~g} / \mathrm{bird} /$ day, birds under LED-R light had the lowest feed consumption. Birds under CFL and incandescent light consumed $103.2 \mathrm{~g} / \mathrm{bird} /$ day and $102.6 \mathrm{~g} / \mathrm{bird} /$ day, respectively, on average (Fig. 4). Regardless of the light source, age had a significant effect on feed consumption $(P<$ 0.0001 ), which steadily increased from 14 to 20 woa and then plateaued until the end of the trial.

\section{Body Weight Gain}

As birds aged, there was an increase in body weight (Fig. 5 ) and body weight gain (Fig. 6), regardless of the light source $(P<0.0001)$. Interestingly, correlation analysis revealed that for all treatments, a negative correlation existed between the age at first egg and body weight at 19 woa $(P=0.0006 ; \mathrm{r}$ 
A

Egg Weights
- Inca $\square \mathrm{CFL}$ 日 LED-R

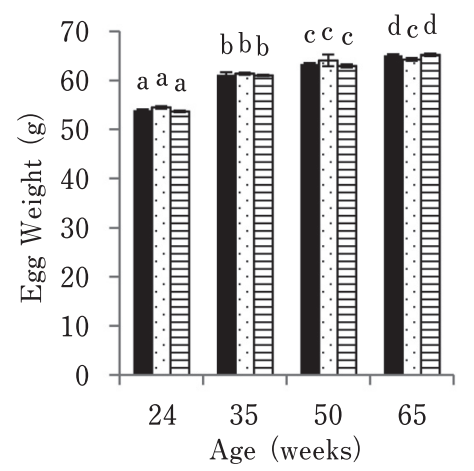

B Shell Strength

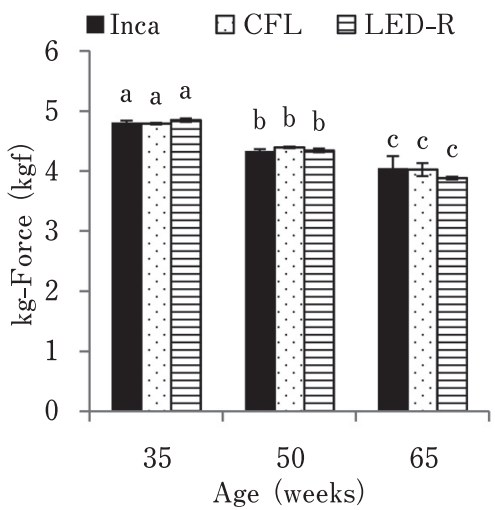

Fig. 3. Weight and shell strength of eggs from hens maintained in individual cages under different light sources. (A) Eggs from individual birds were weighed over four consecutive days at $24,35,50$, and 65 woa. Egg weights increased significantly as birds aged $(P<0.0001)$. (B) Egg shell strength was measured by the Egg Force Reader as $\mathrm{Kg}$ of force required to crack the egg for each individual birds over four consecutive days at 35,50 , and 65 woa. Overall, age had a significant effect where shell strength decreased as birds aged for all treatments $(P$ $<0.0001)$. Different superscript letters indicate significant differences $(P<0.05)$ between collection dates.

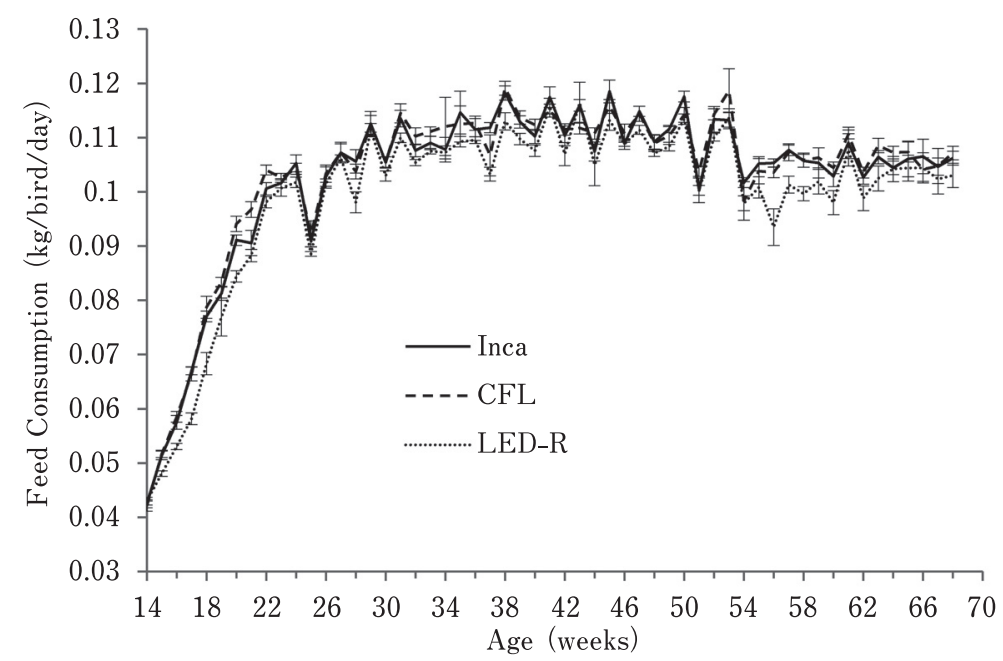

Fig. 4. Feed consumption of hens maintained in individual cages under different light sources. Feed consumption was measured weekly from containers assigned to groups of eight hens (12 containers per room). Overall, age had a significant effect on feed consumption $(P<$ 0.0001 ) as birds consumed more feed overtime.

$=-0.2009)$. This correlation was no longer observed as of 20 woa $(P=0.5904 ; \mathrm{r}=-0.03185)$.

Electric Energy Consumption and Radiant Flux of the Various Light Bulbs

To detect any changes in light output, the spectrum and energy were measured using a spectrophotometer throughout the trial (Fig. 7, Table 2). Overall, the LED-R bulbs were the least energy-consuming, followed by CFL and incandescent bulbs (incandescent: 1,210 kW/h; CFL: $202.8 \mathrm{~kW} / \mathrm{h}$; LED-R: $152.7 \mathrm{~kW} / \mathrm{h})$. Although light intensity was set to 10 lux in each room, there was a difference between the amounts of energy emitted per bulb. LED-R bulbs produced more 


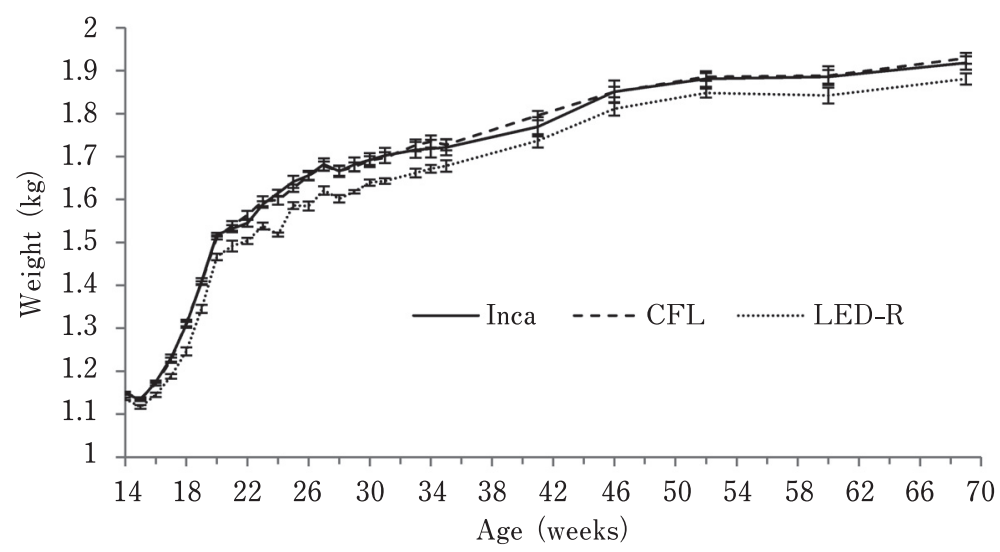

Fig. 5. Average body weight of hens maintained in individual cages under different light sources. Body weight was measured throughout the trial. Overall, body weight increased with age, regardless of the light source $(P<0.0001)$.

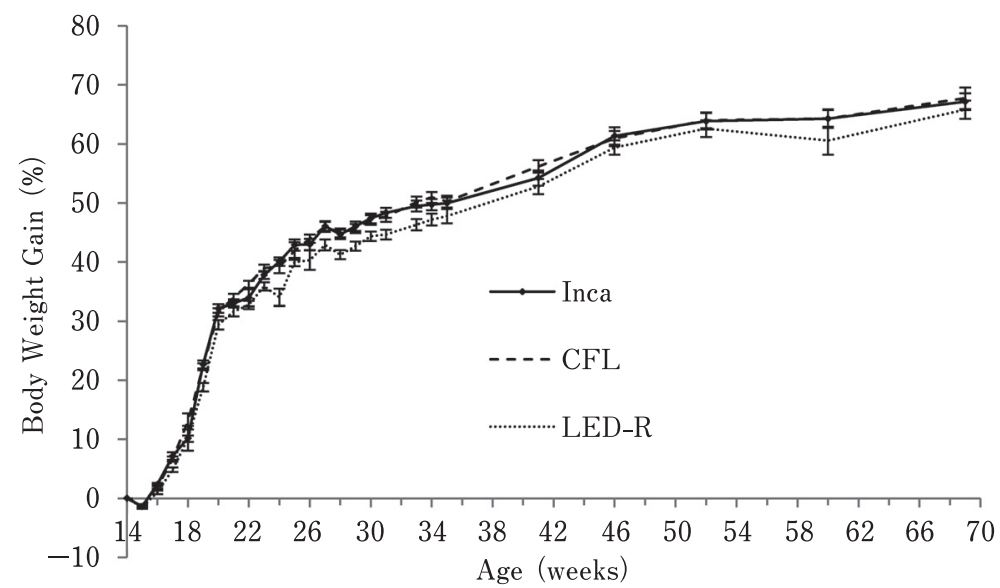

Fig. 6. Body weight gain of hens maintained in individual cages under different light sources. Body weight gain was measured by subtracting the initial body weight from the body weight at each time of measurement throughout the trial. Overall, body weight gain increased with age, regardless of the light source $(P<0.0001)$.

energy than incandescent and CFL lights, and incandescent lamps emitted more energy than CFL bulbs (incandescent: $7.37 \pm 0.84 \mathrm{nW} / \mathrm{bulb} ; \quad$ CFL: $2.25 \pm 0.34 \mathrm{nW} / \mathrm{bulb} ;$ LED-R: $15.47 \pm 1.94 \mathrm{nW} / \mathrm{bulb})$.

\section{Discussion}

With the great advancements in genetic selection in laying hens, optimization of the environmental conditions is vital (Lewis, 2009). This includes light quality (spectrum and intensity) and photoperiod. Previous studies have demonstrated that higher wavelengths more strongly stimulate the reproductive axis in chickens (Gongruttananun, 2011; Hassan et al., 2013; Kim et al., 2013; Baxter et al., 2014; Li et al., 2014) and Japanese quail (Woodard et al., 1969) than shorter wavelengths, whereas other studies have revealed that birds exposed to green light display a delay in sexual maturation (Mobarkey et al., 2010; Gongruttananun, 2011; Hassan et al., 2013; Mobarkey et al., 2013). In fact, the above studies suggest that exposure to red light results in the stimulation of the hypothalamic-pituitary-gonadal axis via deep brain photoreceptors, whereas green light may inhibit reproduction via retinal photoreceptors. In the present study, the spectral output of both incandescent and LED-R bulbs peaked in the red spectrum, whereas that of CFL bulbs peaked in the orange and green spectra, yet, production parameters showed a similar profile regardless of the light source. However, under the study conditions, sexual maturation occurred before the stimulatory photoperiod was 


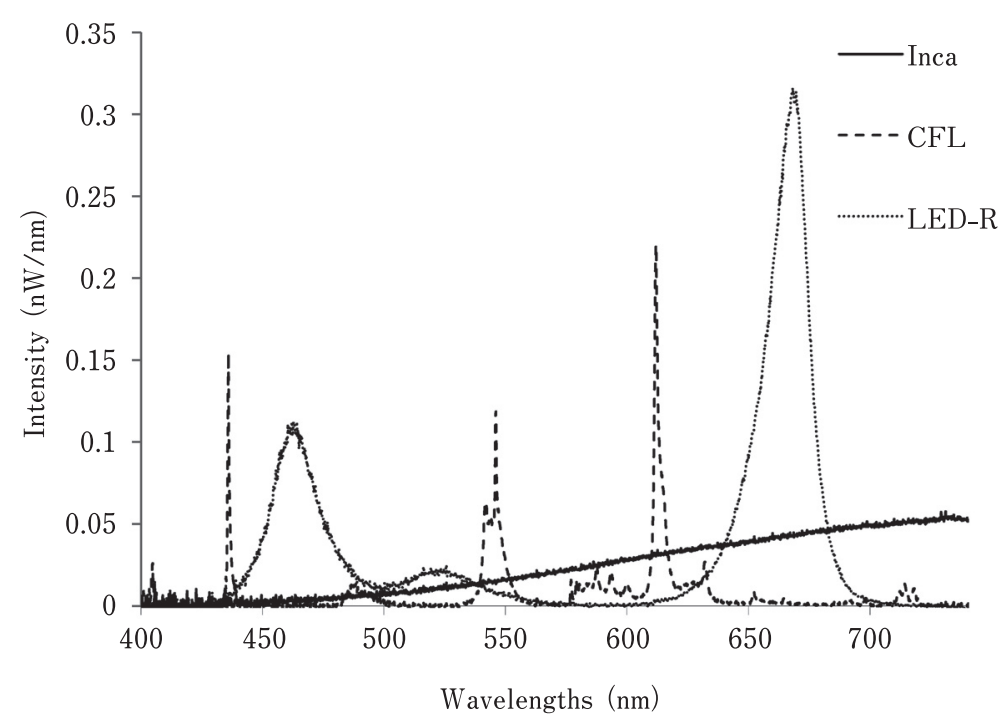

Fig. 7. Spectral output and wavelength peaks from each light source. Representative spectral output recorded with a spectrophotometer, with each light source set to 10 lux.

Table 2. Cumulative energy consumption and average energy emitted for each light source emitted per bulb when set to 10 lux

\begin{tabular}{lcc}
\hline \hline & $\begin{array}{c}\text { Cumulative energy consumption } \\
(\text { Kwh })\end{array}$ & $\begin{array}{c}\text { Energy emitted per bulb } \\
(\mathrm{nW})\end{array}$ \\
\hline Inca & 2,528 & $7.31 \pm 0.93$ \\
CFL & 424 & $2.24 \pm 1.6$ \\
LED-R & 308 & $15.21 \pm 2.3$ \\
\hline
\end{tabular}

reached, suggesting that lighting may not have been the primary trigger for this early onset of lay. The Lohmann LSL-Lite laying hens used in our experiment are a strain of white leghorns heavily selected for egg production and is expected to reach $50 \%$ production between 20 and 21 woa in a cage system (Lohmann Tierzucht, 2013). This suggests these birds may rely on internal factors, such as body weight, to activate the reproductive axis. The impact of metabolic status and body weight on maturity was previously shown in Japanese quail, where birds matured earlier when they reached a critical body lipid level (Zelenka et al., 1984). In a study comparing two strains of Japanese quail divergently selected for early body weight gain, entry in lay occurred as birds reached $90 \%$ of their adult body weight, irrespective of the strain (Hyankova and Novotna, 2007). In leghorns, early-maturing hens began laying at a similar body weight to that of hens that matured later, indicating that there is a relation between body weight of birds and initiation of lay (Dunnington and Siegel, 1984). Eitan et al. (1998) found that restricted feeding slightly, albeit not significantly, delayed the onset of lay in layers, suggesting that birds had met their threshold body weight to initiate lay. Interactions between body weight, fat deposition, and sexual maturation following photostimulation have also been reported in broiler breeders (Pishnamazi et al., 2014). In our study, a negative correlation was observed between body weight and age at first egg, where an earlier age at first egg (in days) correlated with a higher body weight $(\mathrm{kg})$ at 19 woa, regardless of the light source.

Overall, birds under LED-R lights had the highest average levels of estradiol. Interestingly, the first peak in estradiol occurred at 16 woa, approximately 3 weeks before photostimulation, supporting the hypothesis that activation of the hypothalamic-pituitary-gonadal axis does not depend on the photoperiod. Unexpectedly, at 52 woa, a second increase in estradiol was observed in all groups, although it was only statistically significant in birds under LED-R light. The cause of this second increase in estradiol, and whether it originated from stimulatory input at the level of the hypothalamus/pituitary or was initiated locally at the level of the ovary, remain unknown. Recently, breeding companies have increased the selection pressure to extend the laying persistency of commercial strains beyond 100 woa, and it is possible that a spontaneous second wave of follicular recruit- 
ment may occur later in the cycle. In a study by Johnson et al. (1986), there was no difference in serum estradiol concentrations between old (53-63 woa) and young mature hens (28-38 woa). However, as birds aged, estradiol levels in the preovulatory follicles decreased, leading to longer intervals between ovulation, which resulted in decreased egg production (Johnson et al., 1986). In the present study, all hens were still above $90 \%$ production by the end of the trial, and although this is a very interesting finding, the cause, source, and regulation of this late increase in estradiol will require further investigations. Nonetheless, the fact that only the LED-R light resulted in a statistically significant increase supports our previous findings that red light is more efficient at stimulating the production of estradiol than light of other wavelengths (Baxter et al., 2014), possibly by more strongly stimulating the hypothalamic photoreceptors late in the production cycle. A relation between tissue penetrability and energy from light has been previously proposed, as the effect of higher wavelengths appeared more prominent during the second laying cycle, after birds were molted, because peripheral tissues are harder to penetrate with increasing age (Pyrzak et al., 1987). This is in line with results from another study, where leghorns exposed to red light at 72 woa and onward had significantly higher production than birds exposed to incandescent light (Reddy et al., 2012). Therefore, the higher amount of red light in the LED-R light and the resulting higher amount of energy emitted from the bulb may be more efficient at stimulating the reproductive axis than CFL and incandescent light, although the stronger increase in estradiol levels did not translate into higher egg production. Regardless of the light source, the birds produced nearly an egg a day once they reached peak production at 22 woa; it would be difficult physiologically to significantly increase production. Nonetheless, higher estradiol levels may affect other aspects of bird physiology, such as calcium deposition or time of ovulation (Beck and Hansen, 2004; Bain et al., 2016).

As mentioned above, previous studies on non-commercial strains of laying hens indicated that exposing birds to light with higher wavelengths results in higher egg production than maintaining birds under white, green (Pyrzak et al., 1987; Huber-Eicher et al., 2013; Baxter et al., 2014; Li et al., 2014), or blue LED light (Hassan et al., 2013; Kim et al., 2013). Similarly, Japanese quail exposed to red light maintained a higher rate of production than birds exposed to blue and green lights until 16 woa (Woodard et al., 1969). Further, broiler breeder hens exposed to fluorescent light had a lower level of egg production from 58 woa onward (Ingram et al., 1987). However, using commercial strains of laying hens, Er et al. (2007) found that there was no effect of light treatment on egg production when birds were exposed to either red, green, blue, or white light, although birds under red light had higher production than birds under green and blue light from 38-52 woa. Similarly, in the current study, egg production and the cumulative number of eggs were not affected by the light source, and as incandescent and LED-R lights peak in the red spectrum whereas CFL light peaks in the orange spectrum, it is possible that each light source did deliver a sufficient amount of red light or energy to stimulate the hypothalamic photoreceptors. If this is the case, photostimulation by any of the three light sources would have driven hens to peak production and would thus have overshadowed any effect of light spectrum on egg production. However, although consensus suggests that red light the most strongly stimulates the reproductive axis, whether this effect is mediated by the activation of wavelength-specific photoreceptors or is based on higher energy and thus, penetrability of red light is not known. In our study, the light intensity was set as 10 lux for all sources; however, we are aware that lux, the standard unit used in poultry operations, is not a true measure of intensity, but rather a measure of illuminance standardized to human perception (retinal photoreceptor density), and $\mathrm{W} / \mathrm{m}^{2}$ is a better indicator of true intensity (Lewis and Morris, 2006). As shown in Table 2, the three light sources used in our study vary greatly in energy delivered, although normalized intensity based on $\mathrm{W} / \mathrm{m}^{2}$ would have equalized the energy. Thus, tissue penetration to activate deep-brain photoreceptors, this would have significantly impacted the visual acuity of the birds. Based on the significant difference in relative sensitivity of the retina between human and chicken (Prescott et al., 2003; Lewis and Morris, 2006), normalizing light intensity on the basis of $\mathrm{W} / \mathrm{m}^{2}$ rather than lux would have resulted in overly dimmed light for incandescent and LED-R bulbs or disproportionally bright light for CFL lamps, which would have severely affected the birds' visual environment and thus, their welfare.

Previous findings on the impact of light spectrum on egg quality are somehow contradictory, as no difference in egg weight and shell quality were reported under various monochromatic lights (Hassan et al., 2013) and under daylight supplemented with fluorescent or LED light (Gongruttananun, 2011), whereas Er et al. (2007) found that eggs were heaviest under white light, and lightest under red light. They also determined that birds under monochromatic green light produced eggs with stronger shells than those under white or blue light. Others have reported that laying hens under blue light produced heavier eggs than birds under red or white light from 41-50 woa (Kim et al., 2013). Shell quality was also reported to be superior when hens were maintained under green light, and egg weights were higher in hens under green and blue light during the first and second laying cycle (Pyrzak et al., 1987). Li et al. (2014) found that birds under red or white light had the heaviest eggs, and hens under blue and green light produced significantly lighter eggs; however, egg shell strength was superior in birds under green light compared to birds under white or blue light (Li et al., 2014). Thus, there is no consensus on the effect of light wavelength on egg quality, and strain, nutrition, and metabolic status may have stronger influences on egg quality than light.

The effect of light wavelength on feed consumption, feed efficiency, and body growth has been studied mainly in broilers. Rozenboim et al. (1999) found that broilers raised under green light had higher body weights from 3 to 20 days, and exposure to blue light significantly increased body 
weight from 20 to 34 days of age. In a follow-up study, Rozenboim et al. (2004) showed that the body weight and growth of broilers were the highest when birds were raised under monochromatic green light until 10 days and then switched to blue light until 46 days, and these effects appeared to be partly mediated by direct stimulation of muscle growth. In addition, higher feed intake and better feed conversion have been reported in broilers under white and yellow LED compared to birds under CFL light (Mendes et al., 2013). However, commercial broilers and layers have been selected for completely different traits and thus, results cannot be extrapolated from one breed to another. Furthermore, broiler birds reach market weight by 6 woa and are thus considered juvenile. Nonetheless, Hassan et al. (2014) also found that laying hens under red light had better feed conversion, which is in line with the results in our trial, as birds under LED-R produced the same number of eggs while consuming less feed. When comparing feed conversion in layers, it is important to consider environmental housing, as energy expenditure directly relates to the level of activity or thermoregulation. In our experiment, all birds were placed in individual cages, so that their energy expenditure relative to activity would be minimal. Still, a higher amount of red light appears to reduce feed intake and to slow down growth. Previous trials conducted by our group yielded similar results; hens maintained under monochromatic green light had a significantly higher body growth rate than birds maintained under red or white light; however, feed consumption was not measured and birds under green light laid significantly fewer eggs (Baxter et al., 2014).

Throughout the trial, spectral output was measured with a spectrophotometer, and the spectral integrity for each bulb remained constant, indicating a stable output. Electric energy consumption $(\mathrm{kW} / \mathrm{h})$ between bulbs did vary and was directly in line with the energy ratings, where the 10W LED-R lamps used less energy than the $15 \mathrm{~W}$ CFL and $100 \mathrm{~W}$ incandescent lamps. The large difference in energy consumption between incandescent and LED-R is a testament of the latter's efficiency, as the majority of energy is wasted as thermal output for incandescent bulbs (Andrews and Zimmermann, 1990), while the high photoelectric conversion efficiency of LED bulbs results in low thermal output, increasing longevity and lowering energy usage (Yeh and Chung, 2009). Energy emitted per bulb was measured as the radiant flux, which is the number of watts emitted per second from the light source (nW) (Prescott et al., 2003). Although maintained at the same intensity (10 lux), the LED-R bulbs had a significantly higher radiant flux than the CFL and incandescent lamps. The variation in radiant flux between the light sources may be due to the intensity distribution. Incandescent and CFL bulbs have a relatively good isotropic intensity distribution (Shaw and Goodman, 2008), whereas an LED bulb with 75 LED elements had the highest intensities of light below the light source, indicating that the LED light intensity is anisotropic (Shaw and Goodman, 2008). Although Shaw and Goodman (2008) used a different light source, the higher energy emitted from the LED bulb may have been due to large clusters of light being detected by the light probe. Therefore, based on previous research performed by Shaw and Goodman (2008), the difference in radiant flux between the bulbs may have been due to the different distribution of light emitted from each of the bulbs.

In conclusion, as previously reported, red light is more efficient at stimulating the reproductive axis than light of other wavelengths as indicated by the higher concentrations of estradiol; however, this did not translate into earlier onset of lay or higher egg production. We did not anticipate that hens would initiate sexual maturation shortly after placement and prior to photostimulation, and display such a high level of laying persistency. This is likely due to the heavy genetic selection for egg production in commercial birds over the last decades, especially, during the last 10 years. As there was a significant correlation between age at first egg and body weight, other internal factors, such as metabolic status, may be more important cues to trigger sexual maturation than photoperiod. Interestingly, we did observe a distinct, second increase in estradiol around 52 woa, which may be linked to the sustained laying persistency, preventing the anticipated progressive decrease in egg production. Based on body growth and feed consumption, our study suggests that in cages, birds under LED-R may have better feed efficiency. Overall, the LED-R bulb used significantly less electricity and emitted a higher radiant flux, which makes it an ideal candidate for use in table egg and breeder operations.

\section{Acknowledgments}

This research was supported in part by the Poultry Industry Council (Guelph, ON, Canada), the Canadian Poultry Research Council (Ottawa, ON, Canada) and Agriculture and AgriFood Canada (Ottawa, ON, Canada) as part of the Poultry Cluster II funding, and by the Ontario Ministry of Agriculture, Food and Rural Affairs (Guelph, ON, Canada).

\section{References}

Andrews DK and Zimmermann NG. A Comparison of EnergyEfficient Broiler House Lighting Sources and Photoperiods. Poultry Science, 69: 1471-1479. 1990.

Bain MM, Nys Y and Dunn IC. Increasing persistency in lay and stabilising egg quality in longer laying cycles. What are the challenges? British Poultry Science, 57: 330-338. 2016.

Baxter M, Joseph N, Osborne VR and Bedecarrats GY. Red light is necessary to activate the reproductive axis in chickens independently of the retina of the eye. Poultry Science, 93: 12891297. 2014.

Beck MM and Hansen KK. Role of estrogen in avian osteoporosis. Poultry Science, 83: 200-206. 2004.

Bedecarrats GY, McFarlane H, Maddineni SR and Ramachandran R. Gonadotropin-inhibitory hormone receptor signaling and its impact on reproduction in chickens. General and Comparative Endocrinology, 163: 7-11. 2009.

Bedecarrats GY. Control of the reproductive axis: Balancing act between stimulatory and inhibitory inputs. Poultry Science, 94: 810-815. 2015.

Benson ER, Hougentogler DP, McGurkn J, Herrman E and Alphin RL. Durability of Incandescent, Compact Fluorescent, and 
Light Emitting Diode Lamps in Poultry Conditions. Applied Engineering in Agriculture, 29: 103-111. 2013.

Bentley GE, Perfito N, Ukena K, Tsutsui K and Wingfield JC. Gonadotropin-inhibitory peptide in song sparrows (Melospiza melodia) in different reproductive conditions, and in house sparrows (Passer domesticus) relative to chicken-gonadotropinreleasing hormone. Journal of Neuroendocrinology, 15: 794802. 2003.

Cao J, Liu W, Wang Z, Xie D, Jia L and Chen Y. Green and Blue Monochromatic Lights Promote Growth and Development of Broilers Via Stimulating Testosterone Secretion and Myofiber Growth. Journal of Applied Poultry Research, 17: 211-218. 2008.

Chignell CF, Sik RH and Bilski PJ. The photosensitizing potential of compact fluorescent vs incandescent light bulbs. Photochemistry and Photobiology, 84: 1291-1293. 2008.

Chowdhury VS, Yamamoto K, Ubuka T, Bentley GE, Hattori A and Tsutsui K. Melatonin Stimulates the Release of GonadotropinInhibitory Hormone by the Avian Hypothalamus. Endocrinology, 151: 271-280. 2010.

Chowdhury VS, Ubuka T and Tsutsui K. Melatonin stimulates the synthesis and release of gonadotropin-inhibitory hormone in birds. General and Comparative Endocrinology, 181: 175-178. 2013.

Dunn IC and Sharp PJ. Photo-induction of hypothalamic gonadotrophin releasing hormone-I mRNA in the domestic chicken: a role for oestrogen? Journal of Neuroendocrinology, 11: 371375. 1999.

Dunnington EA and Siegel PB. Age and Body-Weight at Sexual Maturity in Female White Leghorn Chickens. Poultry Science, 63: 828-830. 1984.

Eitan Y, Soller M and Rozenboim I. Comb size and estrogen levels toward the onset of lay in broiler and layer strain females under ad libitum and restricted feeding. Poultry Science, 77: 15931600. 1998.

Er D, Wang Z, Cao J and Chen Y. Effect of monochromatic light on the egg quality of laying hens. Journal of Applied Poultry Research, 16: 605-612. 2007.

Etches RJ. Reproduction in Poultry. 1st ed. CAB International, University Press, Cambridge. 1996.

Foss DC, Carew LB and Arnold EL. Physiological Development of Cockerels as Influenced by Selected Wavelengths of Environmental Light. Poultry Science, 51: 1922-1927. 1972.

Foster RG and Follett BK. The Involvement of a Rhodopsin-Like Photopigment in the Photoperiodic Response of the Japanese Quail. Journal of Comparative Physiology A-Sensory Neural and Behavioral Physiology, 157: 519-528. 1985.

Gongruttananun N. Influence of red light on reproductive performance, eggshell ultrastructure, and eye morphology in Thainative hens. Poultry Science, 90: 2855-2863. 2011.

Halevy O, Biran I and Rozenboim I. Various light source treatments affect body and skeletal muscle growth by affecting skeletal muscle satellite cell proliferation in broilers. Comparative Biochemistry and Physiology A-Molecular and Integrative Physiology, 120: 317-323. 1998.

Hassan MR, Sultana S, Choe HS and Ryu KS. Effect of monochromatic and combined light colour on performance, blood parameters, ovarian morphology and reproductive hormones in laying hens. Italian Journal of Animal Science, 12: e56. 2013.

Hassan MR, Sultana S, Choe HS and Ryu KS. Effect of Combinations of Monochromatic LED Light Color on the Performance and Behavior of Laying Hens. Journal of Poultry Science,
51: 321-326. 2014.

Huber-Eicher B, Suter A and Spring-Staehli P. Effects of colored light-emitting diode illumination on behavior and performance of laying hens. Poultry Science, 92: 869-873. 2013.

Hyankova L and Novotna B. Divergent selection for shape of growth curve in Japanese quail. 3. Onset of sexual maturity and basic characteristics of early lay. British Poultry Science, 48: 551-558. 2007.

Ingram DR, Biron TR, Wilson HR and Mather FB. Lighting of End of Lay Broiler Breeders - Fluorescent Versus Incandescent. Poultry Science, 66: 215-217. 1987.

Johnson PA, Dickerman RW and Bahr JM. Decreased GranulosaCell Luteinizing-Hormone Sensitivity and Altered Thecal Estradiol Concentration in the Aged Hen, Gallus-Domesticus. Biology of Reproduction, 35: 641-646. 1986.

Kim MJ, Parvin R, Mushtaq MMH, Hwangbo J, Kim JH, Na JC, Kim DW, Kang HK, Kim CD, Cho KO, Yang CB and Choi HC. Growth performance and hematological traits of broiler chickens reared under assorted monochromatic light sources. Poultry Science, 92: 1461-1466. 2013.

Kuenzel WJ, Kang SW and Zhou ZJ. Exploring avian deep-brain photoreceptors and their role in activating the neuroendocrine regulation of gonadal development. Poultry Science, 94: 786798. 2015.

Lewis PD. Photoperiod and Control of Breeding. Biology of Breeding Poultry, 29: 243-260. 2009.

Lewis PD and Morris TT. Poultry Lighting: The Theory and Practice. 1rst edition, Northcot publisher. Andover. 2006.

Li D, Zhang L, Yang M, Yin H, Xu H, Trask JS, Smith DG, Zhang Z and Zhu Q. The effect of monochromatic light-emitting diode light on reproductive traits of laying hens. Journal of Applied Poultry Research, 23: 367-375. 2014.

Lohmann Tierzucht. 2013. Management Guide- Alternative Systems. Web. http://www.ltz.de/de-wAssets/docs/management-guides/ 1tz-mg-alternative-haltung-en1013.pdf.

Maddineni SR, Ocon-Grove OM, Krzysik-Walker SM, Hendricks III GL and Ramachandran R. Gonadotropin-inhibitory hormone $(\mathrm{GnIH})$ receptor gene is expressed in the chicken ovary: potential role of $\mathrm{GnIH}$ in follicular maturation. Reproduction, 135: 267-274. 2008.

Mans C and Taylor WM. Update on neuroendocrine regulation and medical intervention of reproduction in birds. Veterinary Clinics of North America Exotic Animal Practice, 11: 83-105. 2008.

Mendes AS, Paixao SJ, Restelatto R, Morello G.M, de Moura DJ and Possenti JC. Performance and preference of broiler chickens exposed to different lighting sources. Journal of Applied Poultry Research, 22: 62-70. 2013.

Mobarkey N, Avital N, Heiblum R and Rozenboim I. The role of retinal and extra-retinal photostimulation in reproductive activity in broiler breeder hens. Domestic Animal Endocrinology, 38: 235-243. 2010.

Mobarkey N, Avital N, Heiblum R and Rozenboim I. The Effect of Parachlorophenylalanine and Active Immunization Against Vasoactive Intestinal Peptide on Reproductive Activities of Broiler Breeder Hens Photostimulated with Green Light. Biology of Reproduction, 88: article83. 2013.

National Research Council. Nutrient Requirements of Poultry. 9th ed. National Academy Press, Washington, D.C. 1994.

Oishi T and Ohashi K. Effects of Wavelengths of Light on the Photoperiodic Gonadal Response of Blinded-Pinealectomized Japanese-Quail. Zoological Science, 10: 757-762. 1993. 
Ottinger MA and Bakst MR. Endocrinology of the avian reproductive system. Journal of Avian Medicine and Surgery, 9: 242250. 1995.

Pang SF, Ralph CL and Reilly DP. Melatonin in Chicken Brain - its Origin, Diurnal-Variation, and Regional Distribution. General and Comparative Endocrinology, 22: 499-506. 1974.

Pishnamazi A, Renema RA, Zuidhof MJ and Robinson F. Effect of age at photostimulation on sexual maturation in broiler breeder pullets. Poultry Science, 93: 1274-1281. 2014.

Prescott NB, Wathes CM and Jarvis JR. Light, vision and the welfare of poultry. Animal Welfare, 12: 269-288. 2003.

Pyrzak R, Snapir N, Goodman G and Perek M. The effect of light wavelength on the production and quality of eggs of the domestic hen. Theriogenology, 28: 947-960. 1987.

Rangel PL and Gutierrez CG. Reproduction in hens: Is testosterone necessary for the ovulatory process? General and Comparative Endocrinology, 203: 250-261. 2014.

Reddy IJ, David CG, Selvaraju S, Mondal S and Kiran GR. GnRH1 mRNA, LH surges, steroid hormones, egg production, and intersequence pause days alter in birds exposed to longer wavelength of light in the later stages of production in Gallus gallus domesticus. Tropical Animal Health Production, 44: 1311-1317. 2012.

Robinson FE and Etches RJ. Ovarian Steroidogenesis during Follicular Maturation in the Domestic-Fowl (Gallus-Domesticus). Biology of Reproduction, 35: 1096-1105. 1986.

Rozenboim I, Biran I, Uni Z, Robinzon B and Halevy O. The effect of monochromatic light on broiler growth and development. Poultry Science, 78: 135-138. 1999.

Rozenboim I, Biran I, Chaiseha Y, Yahav S, Rosenstrauch A, Sklan $\mathrm{D}$ and Halevy $\mathrm{O}$. The effect of a green and blue monochromatic light combination on broiler growth and development. Poultry Science, 83: 842-845. 2004.

Shaw M and Goodman T. Array-based goniospectroradiometer for measurement of spectral radiant intensity and spectral total flux of light sources. Applied Optometry, 47: 2637-2647. 2008.

Shimizu M and Bédécarrats GY. Activation of the chicken gonadotropin-inhibitory hormone receptor reduces gonadotropin releasing hormone receptor signaling. General and Comparative Endocrinology, 167: 331-337. 2010.

Siopes TD and Wilson WO. Participation of the Eyes in the Photostimulation of Chickens. Poultry Science, 59: 1122-1125. 1980.
Steranka FM, Bhat J, Collins D, Cook L, Craford MG, Fletcher R, Gardner N, Grillot P, Goetz W, Keuper M, Khare R, Kim A, Krames M, Harbers G, Ludowise M, Martin PS, Misra M, Mueller G, Mueller-Mach R, Rudaz S, Shen YC, Steigerwald D, Stockman S, Subramanya S, Trotter T and Wierer JJ. High power LEDs - Technology status and market applications. Physica Status Solidi A-Applied Research, 194: 380-388. 2002.

Terada O, Shimada K and Saito N. Effect of oestradiol replacement in ovariectomized chickens on pituitary LH concentrations and concentrations of mRNAs encoding LH beta and alpha subunits. Journal of Reproduction and Fertility, 111: 59-64. 1997.

Thayananuphat A, Kang SW, Bakken T, Millam JR and El Halawani ME. Rhythmic dependent light induction of gonadotrophin-releasing hormone-I expression and activation of dopaminergic neurones within the premammillary nucleus of the turkey hypothalamus. Journal of Neuroendocrinology, 19: 399-406. 2007.

Ubuka T, Bentley GE, Ukena K, Wingfield JC and Tsutsui K. Melatonin induces the expression of gonadotropin-inhibitory hormone in the avian brain. Proceedings of the National Academy of Sciences of the United States of America, 102: 3052-3057. 2005.

Ubuka T, Ukena K, Sharp PJ, Bentley GE and Tsutsui K. Gonadotropin-inhibitory hormone inhibits gonadal development and maintenance by decreasing gonadotropin synthesis and release in male quail. Endocrinology, 147: 1187-1194. 2006.

Ubuka T, Kim S, Huang Y, Reid J, Jiang J, Osugi T, Chowdhury VS, Tsutsui K and Bentley GE. Gonadotropin-inhibitory hormone neurons interact directly with gonadotropin-releasing hormone-I and -II neurons in European starling brain. Endocrinology, 149: 268-278. 2008.

Woodard AE, Moore JA and Wilson WO. Effect of Wavelength of Light on Growth and Reproduction in Japanese Quail. Poultry Science, 48: 118-123. 1969.

Yeh $\mathrm{N}$ and Chung J. High-brightness LEDs-Energy efficient lighting sources and their potential in indoor plant cultivation. Renewable \& Sustainable Energy Reviews, 13: 2175-2180. 2009.

Zelenka DJ, Cherry JA, Nir I and Siegel PB. Body-Weight and Composition of Japanese Quail (Coturnix-Coturnix-Japonica) at Sexual Maturity. Growth, 48: 16-28. 1984. 